\title{
Global use, utility, and methods of tele-health in COPD: a health care provider survey
}

This article was published in the following Dove Press journal:

International Journal of Chronic Obstructive Pulmonary Disease

\author{
Ahmed M Alrajeh ${ }^{1,2}$ \\ Yousef S Aldabayan ${ }^{1,2}$ \\ Abdulelah M Aldhair ${ }^{1,3}$ \\ Elisha Pickett' ${ }^{\prime}$ \\ Shumonta A Quaderi' \\ Jaber S Alqahtani ${ }^{1,4}$ \\ Marc Lipman' \\ John R Hurst' \\ 'UCL Respiratory, University College \\ London, London, UK; ${ }^{2}$ Department of \\ Respiratory Care, King Faisal University, \\ Al Ahsa, Saudi Arabia; ${ }^{3}$ Department of \\ Respiratory Care, Jazan University, Jazan, \\ Saudi Arabia; ${ }^{4}$ Department of \\ Respiratory Care, Prince Sultan Military \\ College of Health Sciences, Dhahran, \\ Saudi Arabia
}

Introduction: Advances in technology offer various solutions that might help optimize the care provided to patients living with chronic non-communicable diseases such as chronic obstructive pulmonary disease (COPD). However, the efficacy of tele-health in COPD is still controversial. Despite this, there appears to be widespread adoption of this technology.

Aim: To explore the international use of tele-heath for COPD, to assess the perceptions of clinicians employing tele-health in COPD, and to summarize the techniques that have been used by health care providers to personalize alarm limits for patients with COPD enrolled on tele-health programs.

Methods: A cross-sectional survey consisting of 15 questions was distributed and advertised to health care professionals worldwide. Questions were designed to cover five different aspects of tele-health in COPD: purpose of use, equipment type, clinician perceptions, variables monitored, and personalization of alarm limits.

Results: A total of 138 participants completed the survey from 29 different countries. As high as $59 \%$ of the participants had ever used tele-health for COPD, and 33\% still provided tele-health services to patients with COPD. Tele-health was most commonly used for baseline monitoring, with $90 \%$ believing it to be effective. The three most commonly monitored variables were oxygen saturation, heart rate, and the use of rescue medication.

Conclusion: Twenty-nine different countries use tele-health for managing COPD and therefore there is widespread international use of tele-health in COPD. The majority of providers thought tele-health was effective despite evidence to the contrary.

Keywords: chronic obstructive pulmonary disease, COPD, tele-health, home monitoring, alarm limits, perception

\section{Introduction}

The global burden of Chronic Obstructive Pulmonary Disease (COPD) is increasing. According to the World Health Organisation (WHO), 251 million individuals were living with COPD worldwide in $2016 .^{1}$ A total of 3.17 million died from COPD in 2015, making it the 4th leading cause of death worldwide. ${ }^{1,2}$ Data suggest COPD will become the 3 rd leading cause of death by 2030 if no action is taken. ${ }^{3}$

Patients diagnosed with COPD experience exacerbations which, according to the Global Initiative for Chronic Obstructive Lung Disease (GOLD) 2019 report, are "an acute worsening of respiratory symptoms that result in additional therapy". Consequences of exacerbations include more rapid lung function decline, deterioration in quality of life, death, and excess health care expenditure such that intervention to mitigate the burden of exacerbations is important. ${ }^{5,6}$ Studies have shown that outcomes of COPD exacerbations can be improved with different interventions. ${ }^{4-10}$ These
Correspondence: Ahmed M Alrajeh Royal Free Hospital, UCL Respiratory Medicine, Rowland Hill Street, London NW3 2PF, UK

Tel +442077940500 ext 3430I

Fax +44207317 7561

Email rmhaaa2@ucl.ac.uk
International Journal of Chronic Obstructive Pulmonary Disease 2019:14 17/3-17/9

1713

DovePress $f$ in $\boldsymbol{v}$

http://do. org/10.2147/CopDsan 
include establishing early access to therapy as this has been associated with faster symptom recovery and decreased risk of hospitalization. ${ }^{11}$

Tele-health ("the remote exchange of data between a patient at home and their clinician(s) to assist in diagnosis and monitoring typically used to support patients with long term conditions"). ${ }^{12}$ for COPD has the potential to improve patient care and reduce treatment delay during exacerbations. Studies have shown it can be used to detect exacerbations, support education, and enhance the delivery of pulmonary rehabilitation. ${ }^{13-15}$ However, evidence regarding its effectiveness is controversial. ${ }^{16}$ In 2012, Mclean et al conducted a systematic review and examined 10 randomized clinical trials (RCTs): the use of tele-health was associated with a significant reduction in emergency visits and hospitalizations. ${ }^{17}$ In a retrospective study conducted in 2016, the rate of exacerbations was decreased with the use of tele-health (time to next exacerbation ranged from 45 to 190 days, $p=0.0002) .{ }^{18}$ In a more recent review, Tomasic et al concluded that the effectiveness of tele-health was not yet absolute, but that the majority of studies showed a positive effect or similar outcomes to regular care. ${ }^{19}$ Sul et al also conducted a systematic review of tele-health compared to usual care and concluded that the evidence of benefit from tele-health in COPD patients was still unclear. ${ }^{20}$ These studies and reviews underlie the latest statement from the 2019 GOLD report which states that there is not enough evidence to support the benefit of tele-health in COPD. ${ }^{4}$

There may also be adverse events associated with telehealth. A well-conducted RCT conducted in 2016 showed that tele-health was associated with increased hospitalization and home visits. ${ }^{21}$ Furthermore, the effect of tele-health could be negative if used inappropriately, particularly with regard to setting alarm limits for variables such as heart rate, oxygen saturation, blood pressure, and breathlessness. ${ }^{22} \mathrm{We}$ recently conducted and published a survey of tele-health use in the UK and found use to be widespread, diverse, and associated with a significant proportion of false alarms. ${ }^{23}$ How widespread the global use of tele-health for COPD is not clear. We set out to study this and in particular hypothesized that different health care services would be using different methods to set tele-health alarms, with no clear guideline on how to specify the alarm limits for each patient.

\section{Methods}

We constructed a survey consisting of 15 questions (see Supplementary material) and advertised this to health care professionals by circulating a weblink electronically to international contacts (and asking them to share this widely) and promoting the survey through Twitter, WhatsApp, and LinkedIn. The survey was administered via SurveyMonkey ${ }^{\mathrm{TM}}$ between July 2017 and September 2017. The questions were developed by the authors and tested for validity with local health care professionals. A cover statement explained the purpose of this survey. Under the Research Governance Framework (2005) and Health Research Authority (HRA) review, ethics approval was not required, as the study was a voluntary survey of health-care professionals, with no patient involvement.

Questions were designed to cover five different aspects of tele-health in COPD: purpose of use, equipment type, clinician perceptions, variables monitored, and personalization of alarm limits. Regarding the monitored variables, participants were asked to select all those used by their program. We asked about heart rate, oxygen saturation, respiratory rate, blood pressure, temperature, peak flow, hours of CPAP use, hours of NIV use, step count, physical activity, metabolic equivalent data, sleep quality, phlegm, cough, breathlessness, wheeze, use of rescue medication, and participants had the option to add any variables that were not listed as free text. For any variables being used, participants were then asked how the alarm limit for each variable was set from a dropdown list (arbitrary, international guidelines, national guidelines, personalized to the patient, don't know, or not applicable). Participants who indicated that the alarm limit was personalized were asked how this was done. Participants did not have to answer all the questions.

With regard to questions on clinician perception, responses were graded on a Likert scale between 1 (not at all) and 10 (very much so). The Statistical Package for the Social Sciences (SPSS) version 24 was used to analyze the collected responses. $p \leq 0.05$ was accepted as the level of significance.

\section{Results}

A total of 138 participants completed the survey from 29 different countries, across 6 continents. The geographical location of the respondents is shown in Figure 1. The majority were from Saudi Arabia 30/138 (22.0\%) and the United States 29/138 (21.0\%) with the rest 35/138 (25.0\%) from elsewhere. We have not included our previously published UK data in this analysis. Of the respondents, $58 / 65(42 \%)$ were respiratory therapists, $27 \%$ doctors, $15 \%$ miscellaneous, $14 \%$ physiotherapists, and $2 \%$ nurses. Eighty-two out of 138 (59\%) of practitioners had used tele-health for COPD, and currently, 45 (33\%) still 


\section{Geographical location of the participants}

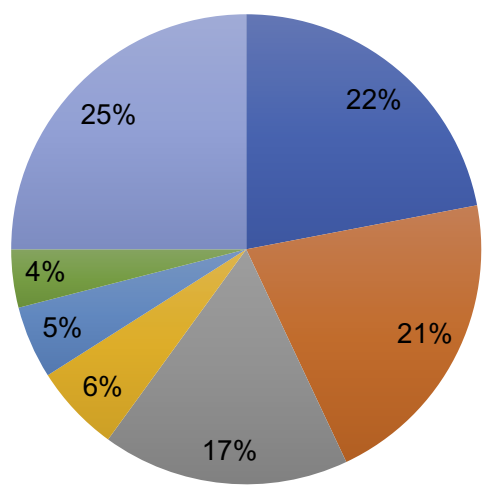

- Saudi Arabia

- United States

- China

- Jordan

- Russia

- Canada

- Other

Figure I The geographical location of the respondents expressed in percentage. Other includes Serbia, Australia, Switzerland, Austria, Italy, Germany, Netherlands, Norway, Denmark, Slovenia, Malta, Ghana, Guyana, Namibia, Pakistan, Philippines, Niger, Singapore, South Africa, Sir Lanka, and Mongolia.

provided tele-health services to patients diagnosed with COPD.

\section{Perception}

In the opinion of the provider, 124/138 (90\%) thought that tele-health was useful for COPD patients with a median (interquartile range (IQR)) score of 8 out of $10(6-10)$ on the Likert scale. In respondents who had used ( $n=81$, median (IQR) 8 (6-9)) versus had not used ( $\mathrm{n}=43$, median (IQR) 8 (6-10)) tele-health, there was no significant difference in perception of utility ( $p=0.454$ ). The providers' perspective of tele-health usefulness in COPD was assessed from their written free-text comments and was based on cost-effectiveness, improved quality of life, self-management, motivation, early detection of exacerbation, prevention of exacerbation, monitoring of exacerbations, prevention of rehospitalization, and avoidance of hospital visits.

\section{Purpose and equipment}

Of the providers who still used tele-health, $43 \%$ used it for baseline monitoring, 34\% for early detection of exacerbations, $31 \%$ for monitoring recovery from an exacerbation, and $18 \%$ for other purposes (some participants used it for more than one purpose). With regard to the equipment used (hardware), more than half of the participants (56\%) used smartphones/tablet app, 28\% a fixed telephone, 16\% a fixed monitoring station, $6 \%$ videophone, and $5 \%$ miscellaneous.

Figure 2 shows the variables most frequently monitored among participants who used tele-health 73/82 (89.0\%). Variables monitored varied between 1\% (CAT \& MRC score) to $86 \%$ (oxygen saturation), but only 10 variables

were reported as monitored by more than $50 \%$ of the respondents. Six were physiological variables and four were symptoms. Oxygen saturation, heart rate, and use of rescue medication were the most common variables.

\section{Alarm limits}

Table 1 shows how the alarm limits were set for each variable. Two techniques were commonly selected by the participants: "National guidelines" or "personalized". With regard to the method of personalization, the participants' answers can be classified into observations taken at time of assessment, historical trend, age/gender, or set as a $20 \%$ change on patient's baseline.

With regard to sensitivity of technique to detect exacerbation, $92 \%$ of the participants responded and $63 \%$ thought their alarm technique was sufficiently sensitive to identify exacerbations. Eighty-two out of 82 participants believed that personalized rather than arbitrary alarm limits made their service more efficient, with a median (IQR) score of 7 (6-8) on the Likert scale.

Figure 3 shows the perceived proportion of false alarms generated by tele-health systems in the opinion of $81 / 138(59 \%)$ participants. The majority believed that $20-$ $60 \%$ of the alarms were false.

\section{Discussion}

We have conducted an international survey to explore the use of tele-health in COPD and to summarize the techniques used by health care providers to personalize alarm limits for COPD patients enrolled in tele-health programs globally. Our key findings are of the 138 responders, 45 (33\%) currently use tele-health, $90 \%$ of the practitioners thought tele-health was useful in COPD, tele-health is most commonly delivered from a smartphones/tablet app, and the most common variables monitored are oxygen saturation, heart rate, and use of rescue medication. The majority of practitioners set alarm limits for these variables based on national guidelines - though we know of no such guidance. For alarm limit personalization, different methods were reported but with no evidence base, particularly for physiological variables.

Even though the efficacy of tele-health in COPD is still in question, the majority of providers believed that telehealth was beneficial for COPD patients, despite the lack of robust evidence, and despite a diverse range of methods and alarm techniques being used. These findings suggest the need for further studies to evaluate why providers' perceptions do not match the current evidence, and the 


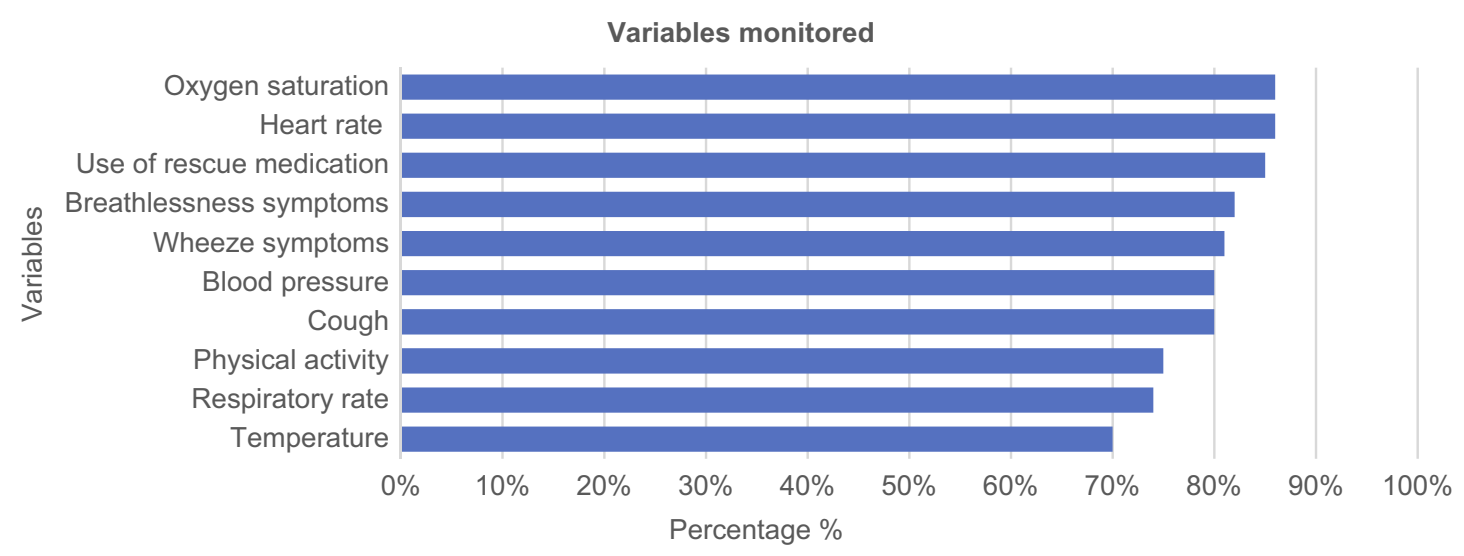

Figure 2 Variables being monitored by tele-health providers.

need for greater awareness among providers about telehealth in COPD and how objectively to assess potential benefits and harms. Ayatollahi et al reported that the lack of knowledge found in health care providers could influence their perception of benefit. ${ }^{24}$

The provision of tele-health services can be achieved through several applications. Based on our findings, smartphones/tablet hardware were the most commonly used. The potential for better monitoring of COPD patients via smartphones is plausible. Ding et al reported that using a smartphone application contributed to a decrease in the number of hospital admissions and emergency department attendances as this could help distinguish changes in symptoms prior to an exacerbation. ${ }^{25} \mathrm{~A}$ recent meta-analysis noted that patients monitored via smartphones tended to have fewer COPD exacerbations compared to conventional care. ${ }^{26}$ Further, Williams et al demonstrated the positive impact of using smartphone apps in increasing the level of self-management and awareness of COPD patients. ${ }^{27}$

Heart rate, oxygen saturation, and use of rescue medication were the most common variables being monitored. In the pilot study conducted by Hurst et al in 2010, we were able to detect a significant change in heart rate and oxygen saturation before exacerbation onset. ${ }^{28}$ The maximum change in heart rate was an increase of 3.09SD and the maximum decrease in oxygen saturation was $-1.24 \mathrm{SD}$ at day 2 of exacerbation. Moreover, in a previous systematic review in 2016, we summarized the potential of monitoring physiological variables for detection of exacerbations. $^{29}$ Whilst demonstrating proof-of-concept, we conclude that there remains the need for more clinical trials assessing the potential for monitoring physiological variables to provide early detection of COPD exacerbations and to reliably distinguish this from dayto-day symptom variation.

Another key factor that may improve the efficacy of tele-health service is the setting of alarm limits. Our findings showed that the majority of providers (89\%) thought personalizing the alarm limits for each patient improved the care provided, and $63 \%$ thought their technique was sufficiently sensitive to detect exacerbations, at the expense of a high proportion of false alarms. The latter could lead to alarm fatigue. ${ }^{30}$ which therefore may affect service quality, patient trust, and cost-effectiveness. Studies have shown that alarm limits are often breached because of technical malfunctions, sensor malpositioning, or changes in therapy rather than clinical deteriorations. ${ }^{31}$ Well-conducted trials will be needed to establish standardized guidelines for personalizing alarm limits for COPD patients enrolled in a tele-health service as the reported personalization methods from providers are not evidence based, even though they were similar to those previously reported in our systematic review. A novel approach to detecting alarm limits in tele-health would be machine learning, which has the potential to increase the efficiency and cost-effectiveness of tele-health. However, none of our participants reported the use of machine learning, even though it has been used in some clinical trials with COPD patients and showed promising results in terms of sensitivity and specificity. ${ }^{19}$

According to our findings, there is widespread international use of tele-health in COPD. In a prior survey conducted by our department restricted to health care providers in England and Wales. ${ }^{23}$ We found similar mismatch between providers' perceptions of tele-health usefulness compared to current evidence, and a high rate of false alarms. There were however some differences in 
Table I The participant's percentage of how alarm limit was set for each variable

\begin{tabular}{|c|c|c|c|c|c|c|c|}
\hline Variables & $\begin{array}{l}\text { Arbitrary/what } \\
\text { feels right }\end{array}$ & $\begin{array}{l}\text { Local } \\
\text { guideline }\end{array}$ & $\begin{array}{l}\text { National } \\
\text { guideline }\end{array}$ & $\begin{array}{l}\text { Personalized (based on data } \\
\text { from that patient) }\end{array}$ & $\begin{array}{l}\text { Don't } \\
\text { know }\end{array}$ & $\begin{array}{l}\text { Not } \\
\text { applicable }\end{array}$ & Total \\
\hline Heart rate & $\begin{array}{l}6 \% \\
3\end{array}$ & $\begin{array}{l}2 \% \\
1\end{array}$ & $\begin{array}{l}53 \% \\
25\end{array}$ & $\begin{array}{l}34 \% \\
16\end{array}$ & $\begin{array}{l}4 \% \\
2\end{array}$ & $\begin{array}{l}0 \% \\
0\end{array}$ & 47 \\
\hline $\begin{array}{l}\text { Oxygen } \\
\text { saturation }\end{array}$ & $\begin{array}{l}7 \% \\
3\end{array}$ & $\begin{array}{l}2 \% \\
1\end{array}$ & $\begin{array}{l}57 \% \\
26\end{array}$ & $\begin{array}{l}28 \% \\
13\end{array}$ & $\begin{array}{l}4 \% \\
2\end{array}$ & $\begin{array}{l}2 \% \\
1\end{array}$ & 46 \\
\hline $\begin{array}{l}\text { Use of } \\
\text { medication }\end{array}$ & $\begin{array}{l}7 \% \\
3\end{array}$ & $\begin{array}{l}5 \% \\
2\end{array}$ & $\begin{array}{l}52 \% \\
23\end{array}$ & $\begin{array}{l}32 \% \\
14\end{array}$ & $\begin{array}{l}2 \% \\
1\end{array}$ & $\begin{array}{l}2 \% \\
1\end{array}$ & 44 \\
\hline $\begin{array}{l}\text { Respiratory } \\
\text { rate }\end{array}$ & $\begin{array}{l}5 \% \\
2\end{array}$ & $\begin{array}{l}5 \% \\
2\end{array}$ & $\begin{array}{l}61 \% \\
26\end{array}$ & $\begin{array}{l}21 \% \\
9\end{array}$ & $\begin{array}{l}5 \% \\
2\end{array}$ & $\begin{array}{l}5 \% \\
2\end{array}$ & 43 \\
\hline Breathlessness & $\begin{array}{l}12 \% \\
5\end{array}$ & $\begin{array}{l}3 \% \\
1\end{array}$ & $\begin{array}{l}49 \% \\
20\end{array}$ & $\begin{array}{l}29 \% \\
12\end{array}$ & $\begin{array}{l}2 \% \\
1\end{array}$ & $\begin{array}{l}5 \% \\
2\end{array}$ & 41 \\
\hline $\begin{array}{l}\text { Blood } \\
\text { pressure }\end{array}$ & $\begin{array}{l}8 \% \\
3\end{array}$ & $\begin{array}{l}10 \% \\
4\end{array}$ & $\begin{array}{l}63 \% \\
25\end{array}$ & $\begin{array}{l}15 \% \\
6\end{array}$ & $\begin{array}{l}5 \% \\
2\end{array}$ & $\begin{array}{l}0 \% \\
0\end{array}$ & 40 \\
\hline $\begin{array}{l}\text { Cough } \\
\text { symptoms }\end{array}$ & $\begin{array}{l}10 \% \\
4\end{array}$ & $\begin{array}{l}8 \% \\
3\end{array}$ & $\begin{array}{l}33 \% \\
13\end{array}$ & $\begin{array}{l}43 \% \\
17\end{array}$ & $\begin{array}{l}3 \% \\
1\end{array}$ & $\begin{array}{l}5 \% \\
2\end{array}$ & 40 \\
\hline Wheeze & $\begin{array}{l}3 \% \\
1\end{array}$ & $\begin{array}{l}3 \% \\
1\end{array}$ & $\begin{array}{l}47 \% \\
18\end{array}$ & $\begin{array}{l}40 \% \\
15\end{array}$ & $\begin{array}{l}3 \% \\
1\end{array}$ & $\begin{array}{l}5 \% \\
2\end{array}$ & 38 \\
\hline $\begin{array}{l}\text { Physical } \\
\text { activity }\end{array}$ & $\begin{array}{l}5 \% \\
2\end{array}$ & $\begin{array}{l}5 \% \\
2\end{array}$ & $\begin{array}{l}43 \% \\
16\end{array}$ & $\begin{array}{l}32 \% \\
12\end{array}$ & $\begin{array}{l}5 \% \\
2\end{array}$ & $\begin{array}{l}8 \% \\
3\end{array}$ & 37 \\
\hline $\begin{array}{l}\text { Hours of NIV } \\
\text { use }\end{array}$ & $\begin{array}{l}6 \% \\
2\end{array}$ & $\begin{array}{l}6 \% \\
2\end{array}$ & $\begin{array}{l}39 \% \\
14\end{array}$ & $\begin{array}{l}31 \% \\
11\end{array}$ & $\begin{array}{l}6 \% \\
2\end{array}$ & $\begin{array}{l}14 \% \\
5\end{array}$ & 36 \\
\hline Temperature & $\begin{array}{l}6 \% \\
2\end{array}$ & $\begin{array}{l}8 \% \\
3\end{array}$ & $\begin{array}{l}70 \% \\
25\end{array}$ & $\begin{array}{l}11 \% \\
4\end{array}$ & $\begin{array}{l}3 \% \\
1\end{array}$ & $\begin{array}{l}3 \% \\
1\end{array}$ & 36 \\
\hline $\begin{array}{l}\text { Phlegm } \\
\text { symptoms }\end{array}$ & $\begin{array}{l}6 \% \\
2\end{array}$ & $\begin{array}{l}6 \% \\
2\end{array}$ & $\begin{array}{l}29 \% \\
10\end{array}$ & $\begin{array}{l}44 \% \\
15\end{array}$ & $\begin{array}{l}6 \% \\
2\end{array}$ & $\begin{array}{l}9 \% \\
3\end{array}$ & 34 \\
\hline Peak flow & $\begin{array}{l}9 \% \\
3\end{array}$ & $\begin{array}{l}3 \% \\
1\end{array}$ & $\begin{array}{l}38 \% \\
13\end{array}$ & $\begin{array}{l}27 \% \\
9\end{array}$ & $\begin{array}{l}3 \% \\
1\end{array}$ & $\begin{array}{l}21 \% \\
7\end{array}$ & 34 \\
\hline $\begin{array}{l}\text { Hours of } \\
\text { CPAP use }\end{array}$ & $\begin{array}{l}3 \% \\
1\end{array}$ & $\begin{array}{l}9 \% \\
3\end{array}$ & $\begin{array}{l}44 \% \\
14\end{array}$ & $\begin{array}{l}22 \% \\
7\end{array}$ & $\begin{array}{l}6 \% \\
2\end{array}$ & $\begin{array}{l}16 \% \\
5\end{array}$ & 32 \\
\hline Step count & $\begin{array}{l}3 \% \\
3\end{array}$ & $\begin{array}{l}6 \% \\
3\end{array}$ & $\begin{array}{l}41 \% \\
3\end{array}$ & $\begin{array}{l}25 \% \\
3\end{array}$ & $\begin{array}{l}3 \% \\
3\end{array}$ & $\begin{array}{l}21 \% \\
3\end{array}$ & 32 \\
\hline Sleep quality & $\begin{array}{l}3 \% \\
1\end{array}$ & $\begin{array}{l}7 \% \\
2\end{array}$ & $\begin{array}{l}36 \% \\
11\end{array}$ & $\begin{array}{l}36 \% \\
11\end{array}$ & $\begin{array}{l}7 \% \\
2\end{array}$ & $\begin{array}{l}13 \% \\
4\end{array}$ & 31 \\
\hline
\end{tabular}

global use compared to England and Wales. Globally smartphone/tablet apps were the most used frequent hardware use, whereas in England and Wales, a fixed monitoring station was the most common method. This draws attention to the variability between the two methods and the impact of this difference in evaluating the cost-effectiveness of tele-health in COPD. Findings from this international survey showed that alarm limits were most frequently set based on guidelines or from known 'normal' limits (for example, heart rate $60-100$ beats $\mathrm{min}^{-1}$ ).

\section{Strengths and limitations}

Our survey has some limitations. The responsibility for delivering tele-health services for COPD worldwide is not clear; thus, we cannot be sure if the survey reached a representative sample of appropriate providers. Although 
Tele-health perceived proportion of false alarms

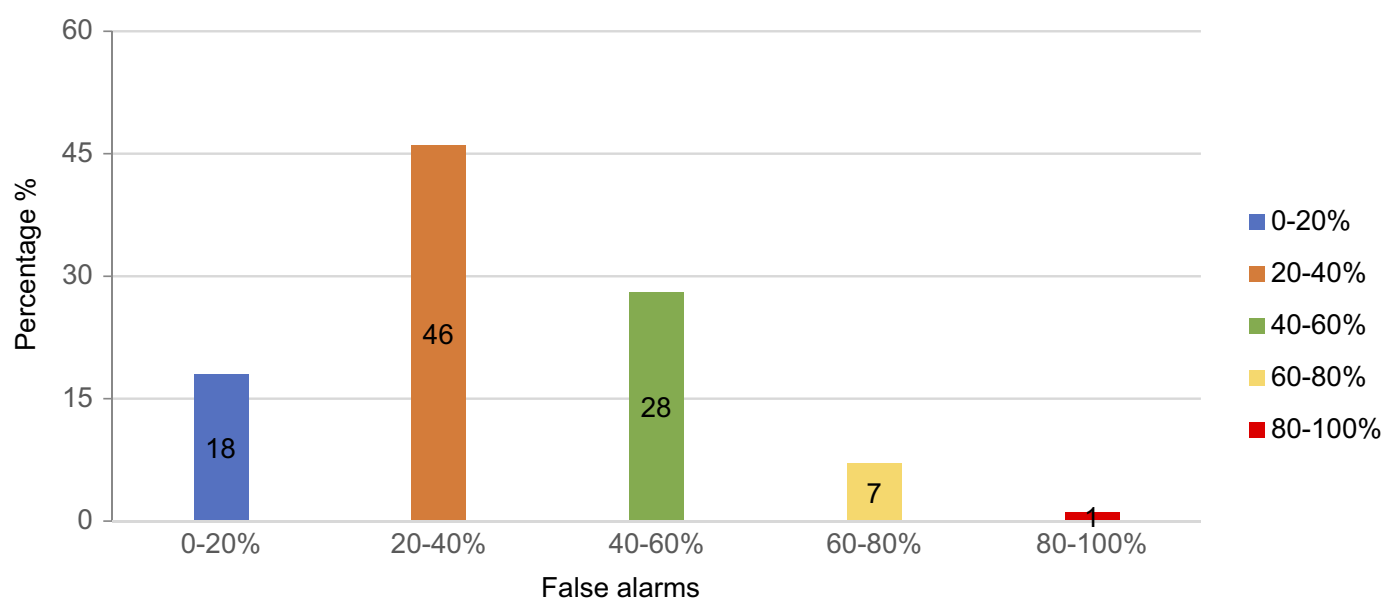

Figure 3 Perceived percentage of false alarms triggered from tele-health systems.

we had wide geographical spread, respondents were concentrated in Saudi Arabia and the United States. The strength of our survey is that, to our knowledge, no previous survey investigating the techniques used for personalization alarm limits, nor the purpose of the use of telehealth with COPD, have been conducted worldwide. It is not clear if prior positive or negative use might bias providers to wish to take part.

\section{Conclusion}

Twenty-nine different countries use tele-health for managing COPD and therefore there is widespread international use of tele-health in COPD. The majority of providers thought telehealth was effective despite evidence to the contrary. Different types of hardware and different non-standardized techniques to personalize alarm limits are used.

\section{Data availability}

We will consider requests for data sharing via e-mail to the corresponding author.

\section{Acknowledgments}

We gratefully acknowledge the American Association for Respiratory Care (AARC) for facilitating the distribution of this survey. King Faisal University through the Saudi Arabian Cultural Bureau in London.

\section{Author contributions}

Al Rajeh and Hurst conceived and designed the study, and distributed the survey. All authors contributed to data analysis, drafting and revising the article, gave final approval of the version to be published, and agree to be accountable for all aspects of the work.

\section{Disclosure}

Professor JR Hurst reports grants, personal fees, non-financial support from Companies that make drugs to treat COPD, outside the submitted work. The authors declare no financial nor non-financial conflicts of interest in this work.

\section{References}

1. World Health Organization. Chronic obstructive pulmonary disease (COPD). 2017. Available from: https://www.who.int/en/news-room/ fact-sheets/detail/chronic-obstructive-pulmonary-disease-(copd). Accessed March 24, 2018.

2. World Health Organization.The Top 10 Causes of Death. 2018. Available from: https://www.who.int/news-room/fact-sheets/detail/ the-top-10-causes-of-death. Accessed June 02, 2018.

3. May SM, Li JT. Burden of chronic obstructive pulmonary disease: healthcare costs and beyond. Allergy Asthma Proc. 2015;36(1):4-10. doi:10.2500/aap.2015.36.3812

4. Global Initiative for Chronic Obstructive Lung Disease. The global strategy for the diagnosis, management, and prevention of chronic obstructive pulmonary disease. GOLD Report. 2019;1:4.

5. Qureshi H, Sharafkhaneh A, Hanania NA. Chronic obstructive pulmonary disease exacerbations: latest evidence and clinical implications. Ther Adv Chronic Dis. 2014;5(5):212-227. doi:10.1177/ 2040622314532862

6. Donaldson GC, Seemungal TAR, Bhowmik A, Wedzicha JA. Relationship between exacerbation frequency and lung function decline in chronic obstructive pulmonary disease. Thorax. 2002;57 (10):847. doi:10.1136/thorax.57.10.847

7. Chronic obstructive pulmonary disease (COPD) statistics. British Lung Foundation. [cited 31 October 2018]. Available from: https://statistics. blf.org.uk/copd?gclid=EAIaIQobChMI9MrxrfmC4AIVRjb TCh2sgAiOEAAYASAAEgIFB_D_BwE.

8. Wilkinson T, Wedzicha JA. Strategies for improving outcomes of COPD exacerbations. Int J Chron Obstruct Pulmon Dis. 2006;1(3):p. $335-42$. 
9. Wentao N, Shao X, Cai X, et al. Prophylactic use of macrolide antibiotics for the prevention of chronic obstructive pulmonary disease exacerbation: a meta-analysis. PLoS One. 2015;10(3):e0121257.

10. Snell N, Hubbard R, Gibson J, Gruffydd-Jones K, Jarrold IS. 32 Epidemiology of chronic obstructive pulmonary disease (COPD) in the uk: findings from the british lung foundation's 'respiratory health of the nation' project. Thorax. 2016;71(3):A20. doi:10.1136/thoraxjnl-2015-207140

11. Wilkinson TM, Donaldson GC, Hurst JR, Seemungal TA, Wedzicha JA. Early therapy improves outcomes of exacerbations of chronic obstructive pulmonary disease. Am J Respir Crit Care Med. 2004;169 (12):1298-1303.

12. The National Telehealth Policy Resource Center. What is telehealth. California health care foundation. [cited 02 May 2018]. Available from: https:/www.chcf.org/topic/telehealth/

13. Dinesen B, Haesum LK, Soerensen N, et al. Using preventive home monitoring to reduce hospital admission rates and reduce costs: a case study of telehealth among chronic obstructive pulmonary disease patients. $J$ Telemed Telecare. 2012;18(4):221-225. doi:10.1258/jtt.2012.110704

14. Kamei T, Yamamoto Y, Kajii F, Nakayama Y, Kawakami C. Systematic review and meta-analysis of studies involving telehome monitoring-based telenursing for patients with chronic obstructive pulmonary disease. Jpn J Nurs Sci. 2013;10(2):180-192. doi:10.1111/j.1742-7924.2012.00228.x

15. Segrelles Calvo G, Gomez-Suarez C, Soriano JB, et al. A home telehealth program for patients with severe COPD: the PROMETE study. Respir Med. 2014;108(3):453-462. doi:10.1016/j.rmed.2013.12.003

16. Pedone C, Lelli D. Systematic review of telemonitoring in COPD: an update. Pneumonol Alergol Pol. 2015;83(6):476-484. doi:10.5603/ PiAP.2015.0077

17. McLean S, Nurmatov U, Liu JL, Pagliari C, Car J, Sheikh A. Telehealthcare for chronic obstructive pulmonary disease: cochrane Review and meta-analysis. Brit J Gen Pract. 2012;62(604):e739-49. doi:10.3399/bjgp12X658269

18. Vitacca M, Paneroni M, Grossetti F, Ambrosino N. Is there any additional effect of tele-assistance on long-term care programmes in hypercapnic COPD patients? A retrospective study. COPD. 2016;13 (5):576-582. doi:10.3109/15412555.2015.1084613

19. Tomasic I, Tomasic N, Trobec R, Krpan M, Kelava T. Continuous remote monitoring of COPD patients-justification and explanation of the requirements and a survey of the available technologies. Med Biol Eng Comput. 2018;56(4):547-569. doi:10.1007/s11517-018-1798-z

20. Sul AR, Lyu DH, Park DA. Effectiveness of telemonitoring versus usual care for chronic obstructive pulmonary disease: A systematic review and meta-analysis. J Telemed Telecare. 2018. $1357633 \times 18811757$. doi:10.1177/1357633X18811757
21. Chatwin M, Hawkins G, Panicchia L, et al. Randomised crossover trial of telemonitoring in chronic respiratory patients (TeleCRAFT trial). Thorax. 2016;71(4):305-311. doi:10.1136/thoraxjnl-2015207140

22. Al Rajeh AM, Obrien M, Symondson J, Hurst JR. Patient specific parameter thresholding to support domiciliary monitoring in COPD. ERJ. 2019;28:PA1035.

23. Al Rajeh AM, Aldhahir A, Pickett E, et al. Methods of tele-health for COPD patients in England and Wales: a health-care provider survey. BMJ Open Respir Res. 2019;6(1):e000345. doi:10.1136/bmjresp2018-000345

24. Ayatollahi H, Sarabi FZ, Langarizadeh M. Clinicians' knowledge and perception of telemedicine technology. Perspect Health Inf Manage. 2015;12:1c.

25. Ding H, Karunanithi M, Kanagasingam Y, Vignarajan J, Moodley Y. A pilot study of a mobile-phone-based home monitoring system to assist in remote interventions in cases of acute exacerbation of COPD. J Telemed Telecare. 2014;20(3):128-134. doi:10.1177/ 1357633X14527715

26. Alwashmi M, Hawboldt J, Davis E, Marra C, Gamble JM, Abu Ashour W. The effect of smartphone interventions on patients with chronic obstructive pulmonary disease exacerbations: a systematic review and meta-analysis. JMIR mHealth and uHealth. 2016;4(3): e105. doi:10.2196/mhealth.5921

27. Williams V, Price J, Hardinge M, Tarassenko L, Farmer A. Using a mobile health application to support self-management in COPD: a qualitative study. Brit J Gen Pract. 2014;64(624):e392-400. doi:10.3399/bjgp14X680473

28. Hurst JR, Donaldson GC, Quint JK, Goldring JJ, Patel AR, Wedzicha JA. Domiciliary pulse-oximetry at exacerbation of chronic obstructive pulmonary disease: prospective pilot study. BMC Pulm Med. 2010;10:52. doi:10.1186/1471-2466-10-52

29. Al Rajeh AM, Hurst JR. Monitoring of Physiological Parameters to predict exacerbations of chronic obstructive pulmonary disease (COPD): a systematic review. J Clin Med. 2016;5(12):25. doi: $10.3390 /$ jcm5120108

30. Sendelbach S, Funk M. Alarm fatigue: a patient safety concern. AACN Adv Crit Care. 2013;24(4):378-386. quiz 87-8. doi:10.1097/ NCI.0b013e3182a903f9

31. Chambrin MC, Ravaux P, Calvelo-Aros D, Jaborska A, Chopin C, Boniface B. Multicentric study of monitoring alarms in the adult intensive care unit (ICU): a descriptive analysis. Intensive Care Med. 1999;25(12):1360-1366.

\section{Publish your work in this journal}

The International Journal of COPD is an international, peer-reviewed journal of therapeutics and pharmacology focusing on concise rapid reporting of clinical studies and reviews in COPD. Special focus is given to the pathophysiological processes underlying the disease, intervention programs, patient focused education, and self management protocols. This journal is indexed on PubMed Central, MedLine and CAS. The manuscript management system is completely online and includes a very quick and fair peer-review system, which is all easy to use. Visit http://www.dovepress.com/testimonials.php to read real quotes from published authors. 